\title{
The interleukin-6 - I74 G/C promoter polymorphism and arterial stiffness; the Rotterdam Study
}

\author{
Mark PS Sie' \\ Francesco US Mattace- \\ Raso $^{2}$ \\ André G Uitterlinden ${ }^{2}$ \\ Pascal P Arp ${ }^{2}$ \\ Albert Hofman' \\ Huibert AP Pols ${ }^{2}$ \\ Arnold PG Hoeks ${ }^{3}$ \\ Robert S Reneman ${ }^{4}$ \\ Roland Asmar ${ }^{5}$ \\ Cornelia M van Duijn' \\ Jacqueline CM Witteman' \\ 'Department of Epidemiology \\ and Biostatistics, ${ }^{2}$ Department \\ of Internal Medicine, Erasmus \\ Medical Center, Rotterdam, \\ The Netherlands; ${ }^{3}$ Department of \\ Biophysics, ${ }^{4}$ Department of Physiology, \\ Cardiovascular Research Institute \\ Maastricht, Maastricht University, \\ Maastricht, The Netherlands; \\ ${ }^{5}$ Cardiovascular Institute, Paris, France
}

Correspondence: Jacqueline CM Witteman

Department of Epidemiology and Biostatistics, Erasmus Medical Center, 's-Gravendijkwal 230, PO Box 2040,

3000 CA Rotterdam, The Netherlands

Tel +3I I0 4087488

Fax +31104089382

Email j.witteman@erasmusmc.nl

\begin{abstract}
Arterial stiffness normally increases with age and has been established as a precursor of cardiovascular disease. Interleukin-6 is a pleiotropic inflammatory cytokine with an important role in the inflammatory cascade, such as up-regulation of C-reactive protein (CRP). The interleukin-6 -174-G/C promoter polymorphism appears to influence levels of inflammatory markers, which have been shown to be associated with arterial stiffness. We studied the association of this polymorphism with levels of interleukin- 6 and CRP and with arterial stiffness. The study ( $\mathrm{n}=3849$ ) was embedded in the Rotterdam Study, a prospective, population-based study. Analyses on the association between the $-174-\mathrm{G} / \mathrm{C}$ polymorphism and pulse wave velocity, distensibility coefficient, and pulse pressure were performed using analyses of variance. Analyses on the levels of inflammatory markers and arterial stiffness were performed using linear regression analyses. Analyses were adjusted for age, sex, mean arterial pressure, heart rate, known cardiovascular risk factors, and atherosclerosis. We found pulse wave velocity to be $0.35 \mathrm{~m} / \mathrm{s}$ higher for CC-homozygotes vs. wildtype GG-homozygotes $(p=0.018)$ with evidence for an allele-dose effect ( $\mathrm{p}$ trend $=0.013$ ), and a similar pattern for pulse pressure ( $\mathrm{p}$ trend $=0.041$ ). No apparent consistent association with the distensibility coefficient was found. CRP levels were associated with pulse wave velocity $(p=0.007)$. In conclusion, the interleukin- $6-174 \mathrm{G} / \mathrm{C}$ polymorphism is associated with increased arterial stiffness and pulse pressure.
\end{abstract}

Keywords: IL-6, CRP, arterial stiffness, pulse wave velocity, distensibility coefficient, pulse pressure

\section{Introduction}

Arterial stiffness increases with age and has been associated with hypertension, diabetes mellitus (DM), end-stage renal disease and atherosclerosis (Avolio et al 1983; Roman et al 1992; Girerd et al 1994; London et al 1990; Wada et al 1994; van Popele et al 2001). Arterial stiffness has recently been established as a predictor of cardiovascular events (Benetos et al 1997; Franklin et al 1999; Boutouyrie et al 2002; Mattace-Raso et al 2006). The extent of the increase in stiffness may depend on various factors, such as genetic variations.

Inflammatory markers have been found to be associated with arterial stiffness (Mattace-Raso et al 2004; Kullo et al 2005; Tomiyama et al 2005; Vlachopoulos et al 2005). Further study into variations in genes in the inflammatory pathway in relation to arterial stiffness may provide more information on potential pathophysiological mechanisms. Indeed, significant heritability estimates have been found for arterial stiffness (Sayed-Tabatabaei et al 2005).

Interleukin-6 (IL-6) is a pleiotropic cytokine with many different functions. It plays an important role in the acute-phase response and inflammatory cascade, such as up-regulation of acute-phase proteins as CRP (Castell et al 1990; Heinrich et al 1990; Nabata et al 1990; Yudkin et al 1999). An association between IL-6 levels and 
increased arterial stiffness has been described (Diamant et al 2005; Mahmud and Feely 2005; Vlachopoulos et al 2005). Also elevated CRP levels have been shown to be associated with increasing pulse pressure and increased arterial stiffness (Mattace-Raso et al 2004; Kullo et al 2005; Tomiyama et al 2005; Vlachopoulos et al 2005). Fishman and colleagues (1998) detected a functional polymorphism in the promoter region of the human IL-6 gene ( $\mathrm{G}->\mathrm{C}, 174$ bp upstream from the start site). This polymorphism appears to influence the IL-6 gene transcription and is associated with elevated CRP levels (Fishman et al 1998; Basso et al 2002; Jenny et al 2002; Vickers et al 2002; Sie et al 2006).

To the best of our knowledge, the IL-6 gene has not been studied in relation to arterial stiffness. We studied the association of the IL-6 -174 G/C promoter polymorphism, measures of arterial stiffness and levels of CRP and IL-6 within the Rotterdam Study.

\section{Methods}

The Rotterdam Study is an ongoing prospective cohort study including 7983 participants of 55 years and older. Its general aims are to investigate determinants of chronic diseases (Hofman et al 1991). During the first phase of this study (1990-1993), all inhabitants of a Rotterdam suburban area (Ommoord) aged 55 years and over were invited to participate in this study. The response rate was $78 \%$. The third examination phase took place from 1997-1999, during which measures of arterial stiffness were performed. Approval of the Medical Ethics Committee of the Erasmus University Rotterdam was obtained for the Rotterdam Study. From all participants written informed consent was acquired. A more in depth description of the Rotterdam Study was published previously (Hofman et al 1991).

\section{Genotyping}

Genomic DNA was extracted from samples of peripheral venous blood according to standard procedures. 1-2 ng genomic DNA was dispensed into 384-wells plates using a Caliper Sciclone ALH3000 pipetting robot (Caliper LS, Mountain View, CA, USA). Genotypes were determined using Taqman allelic discrimination assay. The Assay-byDesign service (www.appliedbiosystems.com) was used to set up a Taqman allelic discrimination assay for the IL-6 -174 G/C polymorphism (Primers: Fw. GACGACCT AAGCTGCACTTTTC, Rv. GGGCTGATTGGAAACCTTATTAAGATTG. Reporter 1 sequence VIC CTTTAGCATGGCAAGAC and reporter 2 sequence FAM CTTTAGCA TCGCAAGAC). The PCR reaction mixture included $2 \mathrm{ng}$ of genomic DNA in a $2 \mu \mathrm{l}$ volume and the following reagents: FAM and VIC probes (200 nM), primers (0.9 uM), 2x Taqman PCR master mix (ABgene, Epsom, UK). Reagents were dispensed in a 384-wells plate using the Deerac Equator NS808 (Deerac Fluidics, Dublin, Ireland). PCR cycling reactions were performed in 384 wells PCR plates in an ABI 9700 PCR system (Applied Biosystems Inc., Foster City, CA, USA) and consisted of initial denaturation for 15 minutes at $95^{\circ} \mathrm{C}$, and 40 cycles with denaturation of 15 seconds at $95^{\circ} \mathrm{C}$ and annealing and extension for 60 seconds at $60{ }^{\circ} \mathrm{C}$. Results were analyzed by the ABI Taqman $7900 \mathrm{HT}$ using the sequence detection system 2.22 software (Applied Biosystems Inc.). To confirm the accuracy of genotyping results, randomly selected samples ( $5 \%$ of total sample) were re-genotyped using the same method. No inconsistencies were observed.

\section{Measurement of IL-6 and CRP plasma levels}

Levels of IL-6 and CRP were determined in samples obtained at baseline during the first phase of the Rotterdam Study. The methods were described previously (Sie et al 2006).

\section{Arterial stiffness}

In this study three measures of arterial stiffness were used: the carotid-femoral pulse wave velocity (PWV; or aortic stiffness) as a measure of aortic stiffness and the distensibility coefficient (DC; or carotid stiffness) of the common carotid artery as a measure of common carotid arterial stiffness. In addition, pulse pressure (PP) was assessed as an indicator of arterial stiffness. All measures were obtained on the same day, during the same session, during the third follow-up examination.

Carotid-femoral PWV (m/s) was measured using an automatic device (Complior, Colson) and was calculated as the ratio between the distance travelled by the pulse wave and the foot-to-foot time delay.

Common carotid artery distensibility was assessed by measuring the vessel wall motion of the right common carotid artery using a duplex scanner (ATL Ultramark IV, operating frequency $7.5 \mathrm{MHz}$ ) connected to a vessel wall movement detector system (Hoeks et al 1990; Kool et al 1994). The cross-sectional arterial wall distensibility coefficient (DC) (1/MPa) was calculated as a measure of arterial stiffness. A decreased distensibility coefficient implies increased carotid stiffness.

Pulse pressure (PP) (mm Hg) was defined as the difference between systolic and diastolic blood pressure, using the mean systolic and diastolic blood pressure of two 
measurements obtained by measuring blood pressure on the right arm using a random-zero sphygmomanometer.

Details on all measures of stiffness, have been described previously (van Popele et al 2001; Mattace-Raso et al 2006).

\section{Clinical characteristics}

Information on cardiovascular risk factors was collected during the third follow-up examination by trained investigators. Data on drug use and smoking habits were obtained during the home interview. Smoking was classified as never, former, or current smoking. At the research center, measurements were performed by skilled personnel using standardized procedures and calibrated equipment, as described previously (Hofman et al 1991). Blood pressure was measured twice on the right arm using a random-zero sphygmomanometer. The average of the two blood pressure values was used in the analyses. Length and weight were measured and body mass index (BMI) $\left(\mathrm{kg} / \mathrm{m}^{2}\right)$ was calculated. Serum total cholesterol and high-density lipoprotein (HDL) cholesterol values were determined by an automated enzymatic procedure (Boehringer Mannheim System). Diabetes mellitus (DM) was defined as use of antidiabetic medication and/or a fasting serum glucose level of equal to or above $7.0 \mathrm{mmol} / \mathrm{L}$ (DCDM 1997). Evaluation of the atherosclerotic status of participants was accomplished using ultrasonography (carotid intima-media thickness [IMT]) and radiography (aortic calcification); the methods used, are similar to those that have been extensively described previously (Bots et al 1994, 1997; Witteman et al 1994; van Popele et al 2001).

\section{Population for analysis}

A total of 4024 subjects underwent the physical examination of the third phase and PWV was measured in 3550 subjects; 69 subjects $(1.9 \%)$ were excluded from the analyses because of poor quality of the PWV index recordings, leaving 3481 subjects (3207 successfully genotyped) whereas common carotid distensibility was measured in 3098 subjects (2836 successfully genotyped). Pulse pressure measurements could be determined for all subjects participating in the third phase (3833 successfully genotyped). For 2545 genotyped subjects, complete data on both PWV, distensibility coefficient and pulse pressure were available. For 3849 genotyped subjects, data were available on one or more measures of arterial stiffness. Missing information on measures of arterial stiffness was almost entirely due to logistic reasons.

\section{Statistical analyses}

Chi-square tests were performed to test for deviations from Hardy-Weinberg equilibrium. Missing data in clinical characteristics were imputed using Expectation-Maximization algorithms available in SPSS (SPSS Inc., Chicago, IL, USA). For serum measurements all values above mean plus three times the standard deviation were excluded, as correction for outliers. Natural-log transformed (ln-transformation) values of IL- 6 and CRP levels were used to normalize the distribution of these variables. The association between genotypes and arterial stiffness was investigated using analyses of variance. Analyses on the association of IL-6 and CRP levels and arterial stiffness were performed using linear regression. All analyses were adjusted for age and sex, and (if applicable) additionally for mean arterial pressure (MAP), heart rate, BMI, HDL and total cholesterol levels, smoking, DM. and measures of atherosclerosis (carotid IMT and aortic calcification). A p-value of 0.05 and smaller was considered significant in all analyses. The statistical analyses were performed using SPSS version 11.0.1 for MS-Windows (SPSS Inc.).

\section{Results}

General characteristics are described in Table 1 (ln-transformed data are back transformed). Genotype and allele proportions were in Hardy Weinberg equilibrium $(\mathrm{p}=0.18)$.

The C-allele of the $-174 \mathrm{G} / \mathrm{C}$ polymorphism (frequency: $40 \%$ ) was significantly associated with an increased PWV, with evidence for an allele-dose effect (Figure 1). After adjustment for age, gender, MAP, and heart rate, this trend was significant (model 1, p =0.016), and remained significant after further adjustment for cardiovascular risk factors (model 2, $\mathrm{p}=0.024)$, and atherosclerosis (model 3, $\mathrm{p}=0.018$ ). The association was lost after additional adjustment for levels of IL-6 and CRP (data not shown). Those with the CC-genotype had a (significantly) $0.35 \mathrm{~m} / \mathrm{s}$ higher PWV than those with the wildtype GG genotype (model 1, p =0.013; model 2 , $\mathrm{p}=0.018 ;$ model 3, $\mathrm{p}=0.013$ ) (Figure 1).

In the analyses of the association of the IL-6 polymorphism and the carotid distensibility coefficient no significant trends (model $1, \mathrm{p}=0.701$, model $2, \mathrm{p}=0.579$, model $3, p=0.597)$, or differences between the genotypes were found (Figure 1).

The C-allele of the $-174 \mathrm{G} / \mathrm{C}$ polymorphism, however, was significantly associated with an increased pulse pressure, with evidence for an allele-dose effect (Figure 1). After adjustment for age and gender this trend was significant (model $1, \mathrm{p}=0.036$ ), and remained significant after further adjustment for cardiovascular risk factors (model 2, $\mathrm{p}=0.049$ ) and atherosclerosis (model 3, p = 0.041). Those with the CC-genotype had a (significantly) $2.0 \mathrm{~mm} \mathrm{Hg}$ higher 
Table I Population characteristics by IL6-I74 G/C genotype

\begin{tabular}{|c|c|c|c|c|}
\hline \multicolumn{2}{|c|}{ Characteristic } & GG & GC & CC \\
\hline \multicolumn{2}{|c|}{ Total number - No. (\%) } & $1390(36)$ & $1830(48)$ & $629(16)$ \\
\hline \multicolumn{2}{|l|}{ Age (yrs) } & $72 \pm 7$ & $72 \pm 7$ & $73 \pm 7$ \\
\hline \multicolumn{2}{|l|}{ Male sex (\%) } & 42 & 43 & 41 \\
\hline \multicolumn{2}{|l|}{$\mathrm{BMI}\left(\mathrm{kg} / \mathrm{m}^{2}\right)$} & $27 \pm 4$ & $27 \pm 9$ & $27 \pm 4$ \\
\hline \multicolumn{2}{|c|}{ Systolic blood pressure $(\mathrm{mm} \mathrm{Hg})$} & $|43 \pm 2|$ & $143 \pm 22$ & $144 \pm 2 \mid$ \\
\hline \multicolumn{2}{|c|}{ Diastolic blood pressure $(\mathrm{mm} \mathrm{Hg})$} & $75 \pm 11$ & $75 \pm 11$ & $75 \pm 11$ \\
\hline \multicolumn{2}{|c|}{ MAP $(\mathrm{mm} \mathrm{Hg})$} & $106 \pm 13$ & $107 \pm 13$ & $107 \pm 13$ \\
\hline \multicolumn{2}{|c|}{ Total cholesterol (mmol/l) } & $5.8 \pm 1.0$ & $5.8 \pm 1.0$ & $5.8 \pm 0.9$ \\
\hline \multicolumn{2}{|c|}{ HDL-cholesterol (mmol/l) } & $\mathrm{I} .4 \pm 0.4$ & $1.4 \pm 0.4$ & $1.4 \pm 0.4$ \\
\hline \multirow[t]{3}{*}{ Smoking (\%) } & Current & 28 & 32 & 30 \\
\hline & Former & 39 & 37 & 38 \\
\hline & Never & 33 & 31 & 32 \\
\hline \multicolumn{2}{|l|}{ Diabetes (\%) } & 8 & 9 & 10 \\
\hline \multicolumn{2}{|l|}{ IMT (mm) } & $0.77 \pm 0.14$ & $0.78 \pm 0.12$ & $0.78 \pm 0.14$ \\
\hline \multicolumn{2}{|c|}{ Aortic calcifications (\%) ${ }^{\mathrm{a}}$} & 22 & 23 & 20 \\
\hline \multicolumn{2}{|l|}{$\mathrm{PWV}(\mathrm{m} / \mathrm{s})$} & $13.4 \pm 2.9$ & $13.5 \pm 3.1$ & $13.8 \pm 3.2$ \\
\hline \multicolumn{2}{|l|}{$\mathrm{DC}(\mathrm{I} / \mathrm{MPa})$} & $10.4 \pm 4.2$ & $10.6 \pm 4.4$ & $10.1 \pm 4.3$ \\
\hline \multicolumn{2}{|l|}{ PP (mm Hg) } & $68 \pm 17$ & $68 \pm 18$ & $69 \pm 17$ \\
\hline \multicolumn{2}{|c|}{ C-reactive protein $(\mathrm{mg} / \mathrm{L})^{\mathrm{b}, \mathrm{d}}$} & $2.2 \pm 2.3$ & $2.6 \pm 2.8$ & $2.5 \pm 2.7$ \\
\hline \multicolumn{2}{|c|}{ Interleukin-6 $(\mathrm{pg} / \mathrm{mL})^{\mathrm{c}, \mathrm{d}}$} & $2.1 \pm 1.5$ & $2.3 \pm 1.7$ & $2.2 \pm 1.8$ \\
\hline
\end{tabular}

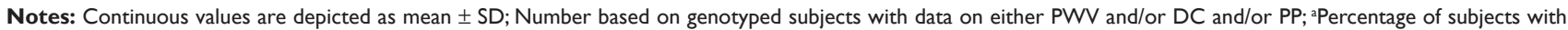
aortic calcification over a length of $\geq 2.5 \mathrm{~cm}$; 'Data available for 3556 subjects ( $\mathrm{n}=1285$ [GG], $\mathrm{n}=1694$ [GC], $\mathrm{n}=577$ [CC]); 'Based on random subgroup ( $\mathrm{n}=158$ [GG], $n=212$ [GC], $n=63$ [CC]); ${ }^{d}$ Measured in samples obtained during first phase of Rotterdam Study.

Abbreviations: BMI, body mass index; DC, distensibility coefficient; IMT, intima media thickness; MAP, mean arterial pressure; PP, pulse pressure; PWV, pulse wave velocity; SD, standard deviation.

pulse pressure than those with the wildtype GG genotype (model 1, $\mathrm{p}=0.037 ;$ model 2, $\mathrm{p}=0.048 ; \operatorname{model} 3, \mathrm{p}=0.041$ ) (Figure 1).

The association between the IL- $6-174$ G/C polymorphism and PWV, the distensibility coefficient and pulse pressure was also analyzed in strata of age $(<73$ years and $\geq 73$ years, with 73 years being the median age). These analyses yielded essentially the same findings as the age-combined analyses (data not shown).
After adjustment for age, gender, MAP, and heart rate, the level of CRP was significantly associated with PWV (regression coefficient [natural log transformed] $0.208 \mathrm{mg} / \mathrm{L}, 95 \%$ CI $0.119-0.298$ ) (Table 2). This association remained significant after adjustment for other cardiovascular risk factors and measures of atherosclerosis (Table 2). An inverse relation of CRP levels and the distensibility coefficient was shown, but was lost after full adjustment (Table 2).

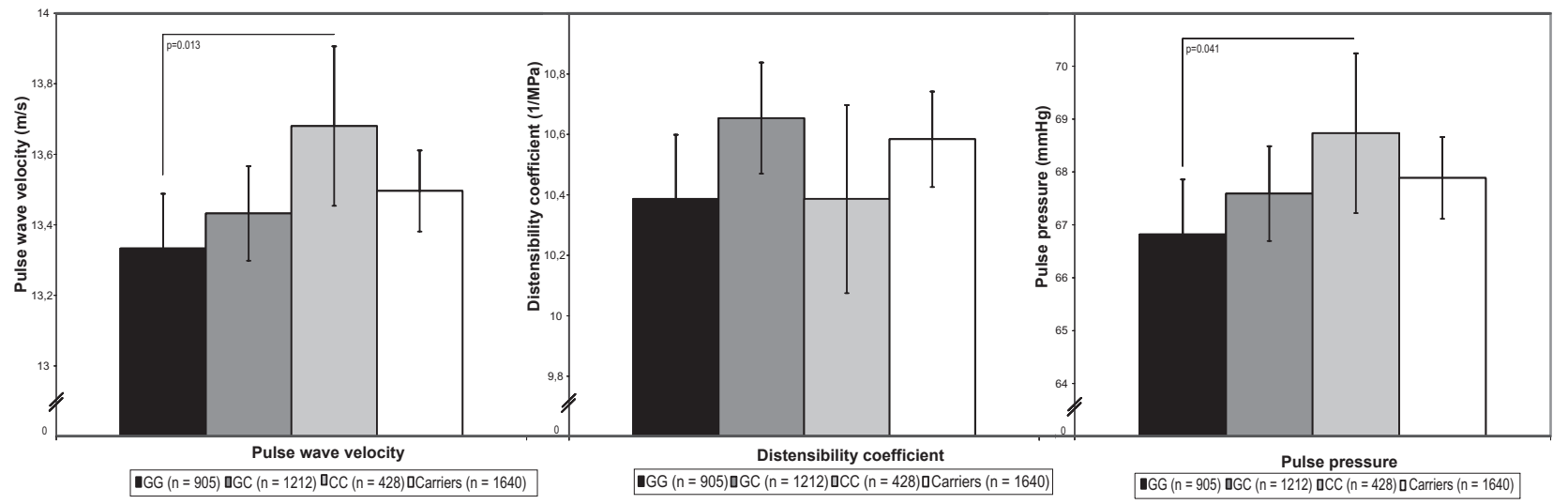

Figure I Association of IL-6 - I74 G/C and measures of arterial stiffness.

Notes: Analyses adjusted for age, sex, body mass index, total cholesterol, high density lipoprotein-cholesterol, diabetes mellitus, smoking, and measures of atherosclerosis (and for pulse wave velocity and the distensibility coefficient for heart rate and mean arterial pressure); Vertical lines depict the $95 \%$ confidence interval; Pulse wave velocity: p for trend 0.018/pulse pressure: $p$ for trend 0.041 . 
Table 2 Association of pulse wave velocity (PWV) and distensibility coefficient (DC) with levels of C-reactive protein

\begin{tabular}{llll}
\hline PWV $(\mathbf{n = 2 9 9 5 )}$ & $\boldsymbol{\beta}$ & $\mathbf{9 5 \%} \mathbf{C l}$ & $\mathbf{P}$ \\
Model I & 0.208 & $0.119-0.298$ & $<0.001$ \\
Model 2 & 0.159 & $0.067-0.250$ & 0.001 \\
Model 3 & 0.124 & $0.034-0.215$ & 0.007 \\
& & & \\
DC $(\mathbf{n}=\mathbf{2 6 3 4 )}$ & $\boldsymbol{9}$ & $\mathbf{9 5 \%} \mathbf{C l}$ & $\mathbf{p}$ \\
Model I & -0.219 & $-0.347--0.091$ & 0.001 \\
Model 2 & -0.098 & $-0.231-0.034$ & 0.147 \\
Model 3 & -0.058 & $-0.191-0.074$ & 0.389
\end{tabular}

Notes: Model I: adjusted for age, sex, heart rate, and mean arterial pressure; Model 2: adjusted for age, sex, heart rate, mean arterial pressure, body mass index, total cholesterol, high density lipoprotein-cholesterol, diabetes mellitus, and smoking; Model 3: adjusted for age, sex, heart rate, mean arterial pressure, body mass index, total cholesterol, high density lipoprotein-cholesterol, diabetes mellitus, smoking, and measures of atherosclerosis; Presented values are natural-log transformed.

IL-6 levels, although only available for a small random sample $(\mathrm{n}=433)$, were also analyzed. The analyses suggested a tendency towards a positive, although nonsignificant, association with PWV, also after adjustment (Table 3). A significant inverse association was found between IL-6 levels and the distensibility coefficient within model 1 (Table 3). After full adjustment, this association remained near significant (Table 3).

All analyses stratified by gender yielded no results essentially different from the overall analyses.

\section{Discussion}

We studied a well-known functional polymorphism in the promoter region of the Interleukin- 6 gene, $-174 \mathrm{G} / \mathrm{C}$ in relation to arterial stiffness. The $\mathrm{C}$-allele of the polymorphism was significantly associated with increased PWV and PP. CRP levels were significantly associated with PWV. Findings on levels of IL-6 also suggested (although not significantly) a tendency toward an association with arterial stiffness.

The $-174 \mathrm{G} / \mathrm{C}$ polymorphism is located in the promotor of the IL-6 gene and may influence gene-transcription. In some studies no effect of this polymorphism on IL-6 and CRP levels was found (Nauck et al 2002; Bennet et al 2003; Bennermo et al 2004; Lieb et al 2004). However, other studies describe it as influencing IL-6 and CRP levels (Fishman et al 1998; Brull et al 2001; Basso et al 2002; Jenny et al 2002; Vickers et al 2002; Bruunsgaard et al 2004). Indeed, in a previous study in the Rotterdam Study, the C-allele was associated with increased CRP levels, but not with IL-6 levels (Sie et al 2006). However, we consider an association with IL-6 levels biologically plausible, and contribute our (nonsignificant) finding to a very small number of IL-6 samples (Sie et al 2006).
Interleukin-6 is a pleiotropic cytokine with many different inflammatory functions, eg, up-regulation of CRP (Castell et al 1990; Heinrich et al 1990; Nabata et al 1990; Yudkin et al 1999). IL-6 levels have been associated with arterial stiffness. Diamant and colleagues (2005) described a positive association of IL-6 and CRP levels and increased arterial stiffness in a small Dutch population $(n=32)$ in both type $2 \mathrm{DM}$ patients as well as in healthy controls. Mahmud and Feely (2005) described an association of IL-6 and CRP levels and PWV in a study of Irish hypertensives $(n=78)$. In a healthy Greek population $(n=100)$, Vlachopoulos and colleagues (2005) also showed IL-6 and CRP levels to be correlated with PWV. In a much larger study of 9867 healthy Americans, CRP levels were associated with pulse pressure, a manifestation of arterial stiffness (Abramson et al 2002). Within the Rotterdam Study, an association between CRP levels and PWV was shown in 866 subjects, which was confirmed in our larger sample of 2995 subjects (MattaceRaso et al 2004). Further, Kullo and colleagues (2005) found a relation between CRP levels and PWV in an American population $(n=214)$.

As CRP and IL-6 levels are associated with arterial stiffness, our findings of a significant association of the polymorphism and increased PWV is biologically plausible. Our significant findings for PP are in concordance herewith. We found no association between the polymorphism and the distensibility coefficient. PWV and the distensibility coefficient both reflect other anatomical regions (the aorta and carotids, respectively), which may contribute to discordances in findings on stiffness. It is also possible, however, that a small effect may have gone undetected due to limitations in sample size.

To assess the influence of age on the relation between the IL-6 polymorphism and arterial stiffness, we also performed

Table 3 Association of pulse wave velocity (PWV) and distensibility coefficient (DC) with levels of interleukin-6

\begin{tabular}{|c|c|c|c|}
\hline $\operatorname{PWV}(n=316)$ & $\beta$ & $95 \% \mathrm{Cl}$ & $\mathbf{p}$ \\
\hline Model I & $0.4 I I$ & $-0.135-0.956$ & 0.139 \\
\hline Model 2 & 0.259 & $-0.300-0.818$ & 0.362 \\
\hline Model 3 & 0.149 & $-0.402-0.701$ & 0.594 \\
\hline$D C(n=28 I)$ & $\beta$ & $95 \% \mathrm{Cl}$ & $\mathbf{p}$ \\
\hline Model I & -0.696 & $-1.316--0.076$ & 0.028 \\
\hline Model 2 & -0.631 & $-1.281-0.018$ & 0.057 \\
\hline Model 3 & -0.593 & $-|.237-0.05|$ & 0.071 \\
\hline
\end{tabular}

Notes: Model I: adjusted for age, sex, heart rate, and mean arterial pressure; Model 2: adjusted for age, sex, heart rate, mean arterial pressure, body mass index, total cholesterol, high density lipoprotein-cholesterol, diabetes mellitus, smoking; Model 3: adjusted for age, sex, heart rate, mean arterial pressure, body mass index, total cholesterol, high density lipoprotein-cholesterol, diabetes mellitus, smoking, and measures of atherosclerosis; Presented values are natural-log transformed. 
analyses stratified by age. However, apart from significance (significance was preserved for $\mathrm{PWV}$ in the $\geq 73$ years group and for PP in the $<73$ years group), the analyses yielded the same findings in the same direction and patterns as in the "age-combined" analyses. Therefore, differences in significance may be more likely due to the reduction in group sizes, than due to strong age-dependent influence on the relation between the IL-6 gene polymorphism and arterial stiffness.

We also found a significant association of CRP levels and PWV. The number of currently available CRP levels within the Rotterdam Study was more than three times larger than the number available at the time of our previous analyses; the results of our present study are in concordance with these earlier findings (Mattace-Raso et al 2004). Our findings suggest IL-6 levels to be positively related to PWV, although this association was not significant. IL-6 has been described to be too unstable in time (plasma half-life of less than 2 hours) to be precisely measured (Riches et al 1992; Waage et al 1989). This might explain the lack of a significant association between PWV and IL-6 levels. In addition we have to remark, that the number of subjects with IL-6 measurements (random sample) was very small.

Our study is based on a large ongoing population-based study in a relatively homogeneous population, as $98 \%$ of the participants in our study are Caucasian and are all living in the same suburb of Rotterdam. We adjusted all analyses for established cardiovascular risk factors. The distensibility coefficient has a strong correlation with MAP; a higher MAP in the artery stretches the elastin and collagen fibres in the arterial wall, making the arteries less distensible. Therefore, the analyses were adjusted for MAP.

To interpret the findings correctly, several methodological aspects of the measures of arterial stiffness need to be discussed. First, pulse waves in the carotid artery and the femoral artery travel in opposite directions, while measurements of carotid-femoral PWV is based on the assumption that the pulse wave travels from the carotid artery to the femoral artery. In this way, measuring the distance between the carotid and the femoral artery led to an overestimation of the distance between the sites of the pulse waves, resulting in overestimation of the velocity of the pulse waves. However, variations in anatomy are limited and this error may be considered similar for all subjects examined, therefore we do not think it has seriously biased our results. Second, the distance between the carotid and the femoral artery may be overestimated in (especially adipose) subjects when this distance is measured by tape. To avoid this error we adjusted the analyses for BMI. Third, in computing the carotid distensibility coefficient, we used the brachial PP rather than the carotid PP. Information on comparisons between the carotid and the brachial PP indicates that the carotid PP is lower than the brachial PP but the differences are relatively small (Waddell et al 2001).

Some general remarks: data on measures of stiffness were not available for all subjects who visited the research center. However, missing information was primarily due to logistic reasons, which is likely to be random and thus will not have biased our results. Second, the cross-sectional design of our study limits the ability to infer a causal relationship between the IL-6 -174 G/C polymorphism, inflammation, and arterial stiffness. Any associations do not necessarily imply causality and should be interpreted with reservation. Further, we interpreted our results also in the context of literature and (known) pathophysiology. However, we are also aware that some findings were not significant and may be chance findings. Finally, because our study was performed in a population of predominantly elderly Caucasian subjects, the generalizability of our findings to younger individuals or other ethnicities remains uncertain.

In conclusion, the $\mathrm{C}$-allele of the interleukin- $6-174 \mathrm{G} / \mathrm{C}$ promoter polymorphism is associated with increased PWV and PP. Our results consolidate the finding that CRP levels are associated with PWV in an elderly Dutch population.

\section{Acknowledgments}

This study was supported by NWO (Netherlands Organization for Scientific Research) under grant no. 904-61-196 and under the ASPASIA grant no. 015.000.090, by the Center for Medical Systems Biology and by the European Commission under grant QLK6-CT-2002-02629 (GENOMOS).

\section{Conflicts of interest}

APG Hoeks has received research grants (pressure wave analysis, pulse wave analysis, risk factor evaluation, molecular imaging). RS Reneman has received research grants (pressure wave analysis, pulse wave analysis, risk factor evaluation, molecular imaging). $\mathrm{R}$ Asmar has received a research grant (pharmaceutical industry) and has ownership interest (medical devices company).

\section{References}

Abramson JL, Weintraub WS, Vaccarino V. 2002. Association between pulse pressure and C-reactive protein among apparently healthy US adults. Hypertension, 39:197-202.

Avolio AP, Chen SG, Wang RP, et al. 1983. Effects of aging on changing arterial compliance and left ventricular load in a northern Chinese urban community. Circulation, 68:50-8. 
Basso F, Lowe GD, Rumley A, et al. 2002. Interleukin-6 -174G > C polymorphism and risk of coronary heart disease in West of Scotland coronary prevention study (WOSCOPS). Arterioscler Thromb Vasc Biol, 22:599-604.

Benetos A, Safar M, Rudnichi A, et al. 1997. Pulse pressure: a predictor of long-term cardiovascular mortality in a French male population. Hypertension, 30:1410-15.

Bennermo M, Held C, Green F, et al. 2004. Prognostic value of plasma interleukin- 6 concentrations and the $-174 \mathrm{G}>\mathrm{C}$ and $-572 \mathrm{G}>\mathrm{C}$ promoter polymorphisms of the interleukin- 6 gene in patients with acute myocardial infarction treated with thrombolysis. Atherosclerosis, 174:157-63.

Bennet AM, Prince JA, Fei GZ, et al. 2003. Interleukin-6 serum levels and genotypes influence the risk for myocardial infarction. Atherosclerosis, 171:359-67.

Bots ML, Hoes AW, Koudstaal PJ, et al. 1997. Common carotid intimamedia thickness and risk of stroke and myocardial infarction: the Rotterdam Study. Circulation, 96:1432-7.

Bots ML, Mulder PG, Hofman A, et al. 1994. Reproducibility of carotid vessel wall thickness measurements. The Rotterdam Study. J Clin Epidemiol, 47:921-30.

Boutouyrie P, Tropeano AI, Asmar R, et al. 2002. Aortic stiffness is an independent predictor of primary coronary events in hypertensive patients: a longitudinal study. Hypertension, 39:10-5.

Brull DJ, Montgomery HE, Sanders J, et al. 2001. Interleukin-6 gene $-174 \mathrm{~g}>\mathrm{c}$ and $-572 \mathrm{~g}>\mathrm{c}$ promoter polymorphisms are strong predictors of plasma interleukin-6 levels after coronary artery bypass surgery. Arterioscler Thromb Vasc Biol, 21:1458-63.

Bruunsgaard H, Christiansen L, Pedersen AN, et al. 2004. The IL-6-174G $>$ C polymorphism is associated with cardiovascular diseases and mortality in 80-year-old humans. Exp Gerontol, 39:255-61.

Castell JV, Gomez-Lechon MJ, David M, et al. 1990. Acute-phase response of human hepatocytes: regulation of acute-phase protein synthesis by interleukin-6. Hepatology, 12:1179-86.

[DCDM] Expert Committee on the Diagnosis and Classficiation of Diabetes Mellitus. 1997. Report of the Expert Committee on the Diagnosis and Classification of Diabetes Mellitus. Diabetes Care, 20:1183-97.

Diamant M, Lamb HJ, van de Ree MA, et al. 2005. The association between abdominal visceral fat and carotid stiffness is mediated by circulating inflammatory markers in uncomplicated type 2 diabetes. $J$ Clin Endocrinol Metab, 90:1495-501.

Fishman D, Faulds G, Jeffery R, et al. 1998. The effect of novel polymorphisms in the interleukin-6 (IL-6) gene on IL-6 transcription and plasma IL-6 levels, and an association with systemic-onset juvenile chronic arthritis. J Clin Invest, 102:1369-76.

Franklin SS, Khan SA, Wong ND, et al. 1999. Is pulse pressure useful in predicting risk for coronary heart Disease? The Framingham heart study. Circulation, 100:354-60.

Girerd X, Mourad JJ, Copie X, et al. 1994. Noninvasive detection of an increased vascular mass in untreated hypertensive patients. $\mathrm{Am} \mathrm{J}$ Hypertens, 7:1076-84.

Heinrich PC, Castell JV and Andus T. 1990. Interleukin-6 and the acute phase response. Biochem $J, 265: 621-36$.

Hoeks AP, Brands PJ, Smeets FA, et al. 1990. Assessment of the distensibility of superficial arteries. Ultrasound Med Biol, 16:121-8.

Hofman A, Grobbee DE, de Jong PT, et al. 1991. Determinants of disease and disability in the elderly: the Rotterdam Elderly Study. Eur J Epidemiol, 7:403-22.

Jenny NS, Tracy RP, Ogg MS, et al. 2002. In the elderly, interleukin-6 plasma levels and the $-174 \mathrm{G}>\mathrm{C}$ polymorphism are associated with the development of cardiovascular disease. Arterioscler Thromb Vasc Biol, 22:2066-71.

Kool MJ, van Merode T, Reneman RS, et al. 1994. Evaluation of reproducibility of a vessel wall movement detector system for assessment of large artery properties. Cardiovasc Res, 28:610-14.
Kullo IJ, Seward JB, Bailey KR, et al. 2005. C-reactive protein is related to arterial wave reflection and stiffness in asymptomatic subjects from the community. Am J Hypertens, 18:1123-9.

Lieb W, Pavlik R, Erdmann J, et al. 2004. No association of interleukin-6 gene polymorphism $(-174 \mathrm{G} / \mathrm{C})$ with myocardial infarction or traditional cardiovascular risk factors. Int J Cardiol, 97:205-12.

London GM, Marchais SJ, Safar ME, et al. 1990. Aortic and large artery compliance in end-stage renal failure. Kidney Int, 37:137-42.

Mahmud A and Feely J. 2005. Arterial stiffness is related to systemic inflammation in essential hypertension. Hypertension, 46:1118-22.

Mattace-Raso FU, van der Cammen TJ, Hofman A, et al. 2006. Arterial stiffness and risk of coronary heart disease and stroke: the Rotterdam Study. Circulation, 113:657-63.

Mattace-Raso FU, van der Cammen TJ, van der Meer IM, et al. 2004. C-reactive protein and arterial stiffness in older adults: the Rotterdam Study. Atherosclerosis, 176:111-16.

Nabata T, Morimoto S, Koh E, et al. 1990. Interleukin-6 stimulates c-myc expression and proliferation of cultured vascular smooth muscle cells Biochem Int, 20:445-53.

Nauck M, Winkelmann BR, Hoffmann MM, et al. 2002. The interleukin-6 $\mathrm{G}(-174) \mathrm{C}$ promoter polymorphism in the LURIC cohort: no association with plasma interleukin-6, coronary artery disease, and myocardial infarction. $J$ Mol Med, 80:507-13.

Riches P, Gooding R, Millar BC, et al. 1992. Influence of collection and separation of blood samples on plasma IL-1, IL-6 and TNF-alpha concentrations. J Immunol Methods, 153:125-31.

Roman MJ, Saba PS, Pini R, et al. 1992. Parallel cardiac and vascular adaptation in hypertension. Circulation, 86:1909-18.

Sayed-Tabatabaei FA, van Rijn MJ, Schut AF, et al. 2005. Heritability of the function and structure of the arterial wall: findings of the Erasmus Rucphen Family (ERF) study. Stroke, 36:2351-6.

Sie MP, Sayed-Tabatabaei FA, Oei HH, et al. 2006. Interleukin 6-174 G/C promoter polymorphism and risk of coronary heart disease. Results from the Rotterdam Study and a meta-analysis. Arterioscler Thromb Vasc Biol, 26:212-17.

Tomiyama H, Koji Y, Yambe M, et al. 2005. Elevated C-reactive protein augments increased arterial stiffness in subjects with the metabolic syndrome. Hypertension, 45:997-1003.

van Popele NM, Grobbee DE, Bots ML, et al. 2001. Association between arterial stiffness and atherosclerosis: the Rotterdam Study. Stroke, 32:454-60.

Vickers MA, Green FR, Terry C, et al. 2002. Genotype at a promoter polymorphism of the interleukin- 6 gene is associated with baseline levels of plasma C-reactive protein. Cardiovasc Res, 53:1029-34.

Vlachopoulos C, Dima I, Aznaouridis K, et al. 2005. Acute systemic inflammation increases arterial stiffness and decreases wave reflections in healthy individuals. Circulation, 112:2193-200.

Waage A, Brandtzaeg P, Halstensen A, et al. 1989. The complex pattern of cytokines in serum from patients with meningococcal septic shock. Association between interleukin 6, interleukin 1, and fatal outcome. $J$ Exp Med, 169:333-8.

Wada T, Kodaira K, Fujishiro K, et al. 1994. Correlation of ultrasoundmeasured common carotid artery stiffness with pathological findings. Arterioscler Thromb, 14:479-82.

Waddell TK, Dart AM, Medley TL, et al. 2001. Carotid pressure is a better predictor of coronary artery disease severity than brachial pressure. Hypertension, 38:927-31.

Witteman JC, Grobbee DE, Valkenburg HA, et al. 1994. J-shaped relation between change in diastolic blood pressure and progression of aortic atherosclerosis. Lancet, 343:504-7.

Yudkin JS, Stehouwer CD, Emeis JJ, et al. 1999. C-reactive protein in healthy subjects: associations with obesity, insulin resistance, and endothelial dysfunction: a potential role for cytokines originating from adipose tissue? Arterioscler Thromb Vasc Biol, 19:972-8. 
